\title{
Engaging Students in Critical Thinking and Problem Solving: A Brief Review of the Literature
}

\author{
Nancy J. McCormick (corresponding author) \\ Mathematical Sciences Department, Middle Tennessee State University \\ Murfreesboro, TN 37132, USA \\ Tel: 1-615-898-5763 E-mail: nancy.mccormick@mtsu.edu \\ Linda M. Clark \& Joan M. Raines \\ University Studies Department, Middle Tennessee State University \\ Murfreesboro, TN 37132, USA
}

Received: March 5, 2015 Accepted: Sep 29, 2015 Published: November 1, 2015

doi:10.5296/jse.v5i4.8249 URL: http://dx.doi.org/10.5296/jse.v5i4.8249

\begin{abstract}
Problem solving and critical thinking skills are beneficial across all fields of collegiate studies and provide lasting value in the workplace and everyday life. In problem solving, students employ critical thinking skills in the analyses of problems and the synthesis and applications of previously learned concepts. For decades, researchers and academics have deliberated on ways to engage students in the classroom to train them in these skills. The collective research on teaching critical thinking and problem solving reveal overarching themes, which include student involvement, learning styles, student motivation, and instructor perceptions and behaviors.
\end{abstract}

Keywords: critical thinking, problem solving, collaborative learning, student motivation, learning styles 


\section{Introduction}

Many higher education institutions have been criticized for their lack of adequately preparing and educating students. A significant number of students are not learning problem solving and critical thinking skills that are central to the core goals of general education across all disciplines at the postsecondary level (McLaughlin et al., 2014). These skills will be applicable in workplaces and in numerous life experiences where one is required to think and reason critically. The various constituents in education recognize the importance and lifelong value of teaching critical thinking and problem solving (Haas \& Keeley, 1998; Willingham, 2008). In a follow-up to their longitudinal study involving more than 2,300 undergraduates, Arum, Cho, Kim, and Roksa (2012) reported that among the students surveyed who graduated on time, those with smaller gains in critical thinking skills had higher unemployment rates, higher credit card and student loan debt, and were more likely to be living at home.

The National Council of Teachers of Mathematics in its Commission on Standards for School Mathematics (1989) advocated a focus on critical thinking that involved more problem solving in mathematics classes at all levels. Yet, understanding the value of critical thinking has not made it an easy process to find techniques and instructional tools for teaching the skill to students. Rather, faculty in general have found critical thinking a difficult concept to teach, and it is even suggested that critical thinking is not just a set of skills but a type of thought process (Willingham, 2008). For decades, researchers and academics have deliberated on how to teach these critical skills and how to engage students in critical thought processes. The question often broached is what variables will influence or impact the teaching and learning of these skills (e.g., Johnson, Johnson, \& Smith, 1998).Exactly what skills should be learned, who should teach the skills, and in what courses these skills should appear is debatable; but, it is clear that college students need help developing critical thinking skills (Halpern, 1993).

Learning is described as a social activity that occurs in a collaborative environment wherein a community oflearnersrehearses, clarifies, and reteaches(Relevance of Collaborative Learning, 2014). In particular, critical thinking is a learned skill that requires both training and practice. It is not an inherent ability and requires more than just simple student engagement.Critical thinking requires students to be actively engaged "in the process ofconceptualizing, applying, analyzing, synthesizing, evaluating, and communicating information" (Kim, Sharma, Land, \& Furlong, 2012, p. 225). Instruction using investigative techniques rather than those requiring only rote memorization promotes these higher-order thinking skills (Snyder \& Snyder, 2008).Furthermore, research on teaching critical thinking and problem solving reveals overarching themes of student involvement, learning styles, student motivation (e.g.,Lockwood, 2007; Reiff, 1996), and instructors' perceptions and behaviors (e.g., Haas \& Keeley, 1998; Wulff\&Wulff, 2004).

\section{Student Involvement}

Student involvement in the learning process is a key element of conceptual learning for mathematics and other collegiate studies. The transfer of knowledge through student-to-student discussion plays an integral role in the learning process. Social interaction 
among students is, according to Vygotsky's educational theory, essential for human learning and the acquistion of knowledge is a process of conceptual understanding as opposed to the development of particular skill sets (Kozulin, 2004; Maddux, Johnson, \& Willis, 1997). It is reasonable to expect that students are more likely to succeed when they are actively involved in their learning. In a traditional learning environment, students are more or less receivers of information transmitted to them by the instructor and as such are not actively engaged in thinking about their learning. In this traditional classroom model, students often need to be encouraged to take notes in class and/or participate in classroom discussion and response. Furthermore, this model does not provide opportunities that would encourage or allow students to realize their own control and responsibility in learning. A lecture model enables students to be passive learners with students taking little responsibility for the achievement of learning outcomes, which in turn leads to minimal retention of knowledge (Hamouda\&Tarlochan, 2014). In contrast, collaborative learning is about shared knowledge and accountability not only for the individual but for all members of the group as well. Engaging together in the learning process, students are able to capitalize on one another's strengths and pool technological skills and knowledge to work together to construct understanding. Also, in making sure that all members of the group fully understand a concept, ideas have to bereiterated and/or explained more fully within the group, which leads to a deeper understanding and longer lasting recall for all involved. Collaborative learning described as "the grouping and pairing of students for the purpose of achieving an academic goal" is beneficial in its promotion of a positive interdependence among students and in its contribution to their oral communication and social interaction skills (Gokhale, 1995, p. 22). This implementation of a collaborative learning environment in college classrooms more closely resembles what graduates should expect to encounter in workplaces. Particularly in higher education, research has shown that using problem solving and group learning opportunities increased student involvement in the classroom (e.g., Bowen, 2000; Mahalingam, Shaefer, \&Morlino, 2008).

When students are allowed to work collaboratively to solve problems, they are required to take a more active role in their learning. Critical thinking skills are better developed when students are given opportunities to think for themselves as opposed to being guided along step by step (Effects of Computer-Assisted Instruction, n.d., para. 2). Working collaboratively, students are provided opportunities to analyze and discuss the problem with others in their group. Ideally, they are required to interact with other students' ideas and suggestions, and to think about and communicate to others possible ways to go about solving the assigned problem. This active exchange, clarification, and evaluation of ideas within a group setting not only encourages student involvement; it also fosters critical thinking (Gokhale, 1995). Although there are different opinions regarding how the groups should be established (for example, group size, whether or not students should be assigned to groups by the instructor, or if student characteristics should be taken into consideration), there seems to be agreement about the benefits.

Gokhale (1995) conducted a study in two sections $(n=48)$ of an undergraduate industrial technology course to examine the effectiveness of collaborative learning in enhancing critical 
thinking skills. She gave a common lecture to both sections concurrently so all students would receive the same information and to control for the effects of any extraneous variables. Then, students in one section were randomly assigned to the individual learning group while the other section of students was assigned to the collaborative learning group. Both groups were given the same worksheets consisting of drill and practice and critical thinking items with an explanation of the task to be completed based on whether they were working individually or collaboratively. After completing the task, the students were tested over the material. Gokhale found there was no significant difference between students in the two groups on drill and practice items on the test; however, students in the collaborative learning group performed significantly better on the critical thinking items than those students who studied individually. Through her research, Gokhale concluded that collaborative learning does indeed promote the development of critical thinking and is more beneficial for enhancing problem solving and critical thinking skills.

Magel (1996) wanted to improve the way that introductory statistics courses are taught by using teaching techniques (more specifically a hands-on approach) that would appeal to students with various learning styles, but was also faced with the challenge of having to teach large classes. In 1993, she conducted a study involving students enrolled in her large $(n=140)$ non-calculus based introductory statistics course. Magel identified her goals as (a) to make the class enjoyable to the students; (b) to make the class more relevant to the students; (c) to get the students to participate and take an active role in the class; and (d) to provide an atmosphere that would foster student learning. The class of 140 students met for lecture on Tuesday and Thursday and for lab (conducted by a graduate student in statistics) on Monday. To achieve her goals, Magel reduced the time spent lecturing by not doing as many examples, spending less time reviewing in class, and allowing students to work in small groups to learn the material. She also introduced new material during each class meeting and each student was given a worksheet (which was due at the end of class) to help with new concepts.

To analyze the results of her efforts, Magel used information gathered from two evaluation forms. One evaluation form was given to the class on the last day of class and collected by a graduate student unrelated to the class. This evaluation allowed students to give comments on the course. The other evaluation form was the departmental evaluation given in all courses each semester. Comparing the data on departmental evaluations from previous semesters to her spring 1993 evaluations, Magel reported improvements in her evaluations for the spring 1993 semester. From this instrument, Magel concluded that she had been successful in reaching at least two of her goals for some of her students. That is, students reported enjoying the course and found it more relevant to them as students. Magel reported an increase in average exam scores and a better retention rate than the classes in the rest of her department. Along with increased student involvement, she noted more interaction with students than in other classes she had taught.

Similarly,Mahalingam, Schaefer, and Molino (2008) conducted a study to determine the impact of group problem solving for students enrolled in a chemistry course at a small private university. The chemistry course was originally a lecture course with an optional recitation session. The recitation session was designed to allow students to ask questions of one of the 
faculty members teaching the course. According to Mahalingam et al., the recitation sessions were poorly attended; and those attending would often passively copy solutions. As a result, the researchers wanted to change the class format to reflect the importance of collaboration in the field of science and to mimic this collaboration in the classroom. The researchers noted that it would be difficult to implement group work in the large lecture sections. To facilitate the implementation of group work, changes were made to the structure of the course. With a view towards supplementing the "traditional lecture with collaborative learning in recitation," the course was redesigned to require students to attend the recitation session. Professors' contact hours were effectively reduced from eight hours (six hours lecture and two hours recitation) to seven hours (three hours lecture and four hours recitation). Statistical comparisons were used to analyze student data (i.e., exam scores and final grades), and student surveys were used to assess students' perceptions of the course. The researchers reported a reduction in the number of students scoring lower than a $60 \%$ average on the exam, an increase in students' responsibility for learning and improved study habits. The researchers concluded that overall group work is an effective way to improve problem solving skills.

\section{Learning Styles}

Several studies have investigated the role learning style plays in the development of critical thinking (e.g., Andreou, Papastavrou, \& Merkouris, 2013; Grant, 2003; Myers \& Dyer, 2006; Torres \& Cano, 1995). Torres and Cano (1995) researched the correlation of field-dependent and field-independent learning styles to the variance in critical thinking abilities among students in the College of Agriculture at Ohio State University. The study found a moderate correlation with $\mathrm{r}=.36$, finding that $9 \%$ of the variance in critical thinking skills were accounted for by learning style. In the study, field-dependent learners were described as perceiving the world in a holistic fashion, experiencing more difficulty in problem solving, favoring a spectator approach to learning, more responsive to social reinforcements, and more extrinsically motivated. This learning style contrasted to the field-independent learners who view the world more analytically, find the solving of problems to be easier, favor independent study, are able to structure their own learning, and are more intrinsically motivated and less responsive to social reinforcement. The description of the field-independent learning style associates more closely to the cognitive behaviors of the higher-order categories described in Bloom's Taxonomy suggesting that these learners have an advantage in problem solving activities. Indeed, the field-independent learning style has long been the traditional orientation of the American school, where analytic, competitive, and individualistic educational formats have been encouraged (Reiff, 1996). Torres and Cano (1995) recommended that teachers assess their own learning style, and that they incorporate a variety of teaching methods, curriculum materials, and evaluation techniques to develop an environment conducive to critical thinking for the different learning styles.

In a later study by Myers and Dyer (2006), the research revealed no significantdifference in the critical thinking abilities of students based on their general learning styles. In this study, a student's primary learning style was established using the Gregorc Style Delineator instrument that identifies the four categories of learning styles as (a) Concrete Sequential, (b) 
Concrete Random, (c) Abstract Sequential, and (d) Abstract Random. Critical thinking skills were assessed using the Cornell Critical Thinking Test, Level Z. If a student's score on the 40-point Gregorc Style Delineator was 33 or higher, then it was defined as a deeply embedded learning style, and further analyzed using the Cornell Critical Thinking Test. The testing of the group of students with deeply embedded learning styles showed a significant difference in critical thinking skills for those learners classified as Abstract Sequential. An implication for teachers is that more direction and focus be given to address the other learning styles. Also, further research is needed for determining what teaching methods will encourage the development of critical thinking abilities in students of all learning styles.

\section{Student Motivation}

Student engagement and motivation go hand-in-hand. That is, rote learning, while teaching basic skills, does little to build student motivation and conceptual understanding. Lai (2011) noted that critical thinking activities could encourage students who are motivated to learn to be persistentwhen faced with a task; and that the challenge of a task may cause students who are less motivated to learn to become more engaged. To increase student engagement and time on task, teachers are encouraged to focus instruction on viable problem-based activities that are learner-centered and that involve the higher-order cognitive intellectual skills, such as critical thinking (Lai, 2011; Norman \&Spohrer, 1996).A study by Rugutt and Chemosit (2009), using a regression model, investigated whether an emphasis on critical thinking skills in the classroom affects student motivation. It was shown that the three factors of student-to-faculty interaction, critical thinking skills, and student-to-student interaction, in that order, were statistically significant predictors of student motivation. After controlling for the other two variables of student-to-faculty and student-to-student interactions, the findings showed that critical thinking skills accounted for six percent of the variance in motivation (Rugutt\&Chemosit, 2009).

The opposing argument is made that students' motivation levels, whichthey bring to the classroom, affect their willingness to engage in problem solving and critical thinking activities. Highly motivated students inherently exhibit greater interest in challenging problems, which then builds on their critical thinking skills. Baron and Pintrich and Schunk (as cited in Hancock, 2004) defined motivation as the force that energizes the desire and then sustains the required behaviors toward the successful pursuit of a predetermined goal. Understanding student motivation has proven to be elusive, but researchers, such as Hancock, have studied student behaviors and identified some student personality variables related to student motivation. This research has examined collaborative learning in connection to a personality variable called peer orientation, which is the extent to which a person prefers to work with others in a collaborative learning situation. The assessment of students' peer orientations might serve to predict the success of individuals participating in group activities. Also, student perception of the purpose and value of a task has been determined to be a critical factor in the level of engagement (Hancock, 2004).

In their study, Garcia and Pintrich (1992) explored the relationship between critical thinking and motivation (intrinsic goal orientation), learning strategies, and classroom experiences. 
The researchers noted that motivation could be divided into two overarching categories, extrinsic and intrinsic goal orientations. Relating it to "shallower levels of information processing" (p. 4) the researchers described extrinsic goal orientation as engaging in tasks based on demonstrating one's ability, doing better than others, or getting a good grade. The researchers related intrinsic goal orientation to "deeper processing" or critical thinking and described it as engaging in tasks based on challenge, interest, or mastery. The study involved students $(\mathrm{N}=758)$ attending three midwestern colleges during the 1987-1988 school year. The institutions were described as a community college, comprehensive university, and small private college. The sample consisted of students enrolled in three biology classes $(n=219)$, three English classes $(n=110)$ and six social science classes $(n=429)$. Participants in the study were given the Motivated Strategies of Learning Questionnaire at the beginning and end of the semester. The posttest differed from the pretest only in that it was inclusive of questions allowing the researchers to gain information about students' perceptions of their classroom experiences.

The researchers found strong positive correlations between critical thinking and motivation and learning strategies at the time of both pretest and posttest. More specifically, they reported a correlation between critical thinking and intrinsic goal orientation $(r=.50$ at time one (pretest); $\mathrm{r}=.57$ at time two (posttest)). Furthermore, Garcia and Pintrich also found a significant difference in means of posttest levels of critical thinking, and pretests and posttests for motivation and learning strategies across disciplines (biology, English, and social science). For further analysis the researchers used multiple regressions and further comparisons and found that motivation is a positive predictor of critical thinking in biology and social science; while learning strategies was a positive predictor of critical thinking in English. In summary, the researchers noted that motivation could be influenced not only by what happens in a classroom, but also across domains.

\section{Instructors' Perceptions and Behaviors}

Faculty perceptions about teaching and learning vary. For various reasons, some instructors have developed a resistance to teaching critical thinking (Haas \& Keeley, 1998; Weissglass, 1993). While many instructors acknowledge the importance of incorporating critical thinking or problem solving opportunities into their courses, they quite often find it difficult to make the changes necessary to do so. Most are not trained in critical thinking methodology and continually struggle to engage students in critical thinking activities.

In a study focused on why critical thinking is so hard to teach, Willingham (2008) explained that critical thinking cannot be separated from the base of knowledge that is necessary to implement the skill. It does not have all of the same characteristics associated with most skills; for example, it is not a skill that is transferrable at any time from situation to situation. Students may be able to think critically in one situation or in one subject, yet not see the connection and applicability to other situations and other subject matter. Even during a single classroom session, students have trouble in thinking how the concepts and techniques studied in an initial exercise connect to subsequent and similar types of exercises. Also, without sufficient background knowledge of a topic, called domain knowledge, the learner is hindered 
in thinking critically about an issue. Furthermore, evolving as a critical thinker requires intentional practice. These characteristics of critical thinking, where thought processes are intertwined with the subject and depend on domain knowledge and practice, makes it difficult to guide students to develop the ability to think critically.

Whether critical thinking is a set of common skills that apply across all subject areas or whether the skills depend on the subject area and the context in which they are taught is still up for debate. Abrami, Bernard, Borokhovski, Wade, Surkes, Tamim, and Zhang (2008) conducted a meta-analysis of 117 empirical studies examining critical thinking instructional approaches that were categorized as general, infusion, immersion or mixed. Findings from their study indicated the mixed approach, which combines subject specific content and independent critical thinking instruction, had the largest effect size and outperformed the other types of instructional approaches. The least effective method was immersion, where students are immersed in subject area content and critical thinking instruction is not explicit. Their findings reinforce the importance of providing explicit instruction in critical thinking and echo what other researchers had previously advocated (e.g., Facione, 1990; Paul, 1992). Additionally, Abrami et al. found that pedagogy does matter when improving students' critical thinking skills. When instructors received training and support while preparing to incorporate critical thinking skills into instruction, better student outcomes were achieved.

Wulff and Wulff (2004) discussed the difficulty in transitioning from lecture only to an interactive style of teaching. The researchers pointed out that resistance to change was often related to instructors' perceptions of teaching and learning. These perceptions are rooted in formal training, preferred ways to learn, and the view that the role of an instructor is to lecture. In their study of an introductory statistics class, Wulff and Wulff indicated that their goal was to use communication to align content, students, and instructor to attain desired learning outcomes in an introductory statistics course. One method incorporated problem solving activities. Using surveys and interviews to gather student feedback, the researchers found that $91 \%$ of the students mentioned problem solving as the method that contributed the most to their learning because it allowed them the opportunitiy to apply the concepts.

There has been much debate regarding critical thinking and whether it is discipline specific or not. Some argue these skills should be incorporated with the teaching of subject specific content and skills; while others feel teaching critical thinking should be taught as a separate entity. Behar-Horenstein and Niu's (2011) review of 42 empirical studies examined how various researchers investigated possible ways to improve students' critical thinking skills using different instructional approaches. Behar-Horenstein and Niu's summary suggested thathow, as well as, in what ways instruction is provided is imperative to bringing about changes in students' critical thinking; and students' skills were more likely to improve when critical thinking was taught explicitly instead of implicitly.Additionally, they found there could be other factors such as the learning environment, the traininginstructors receive, and student-teacher interactions that also affect critical thinking. Whatever method is used, educators "need to understand the processes that constitute critical thinking and use instructional activities aimed at developing these processes" (Behar-Horenstein \& Niu, p. 27). 


\section{Instructional Techniques}

The literature has shown that when students are actively engaged in the learning process, they will be more likely to be successful. One way to accomplish this engagement is through active learning - having students do meaningful activities to become engaged in the learning process. Research has shown that students involved in active learning activities such as discussion, teamwork, self-reflection, and scientific inquiry enhance their learning outcomes, improve their attitudes, and become motivated to acquire knowledge and develop higher-order thinking skills (Baum, 2013; Prince, 2004).

In addition to engaging students through active learning, another teaching model that gets students more actively involved in the learning process is the flipped or inverted classroom. McLaughlin et al. (2014) reported on the results of redesigning a graduate-level health professions course in pharmaceutics by using the flipped classroom model. Students were required to view lectures online and complete assigned reading before coming to class. Time in class was dedicated to activities that included audience response and open questions, pair and share, student presentations and discussion, individual or paired quizzes, and microlectures which were designed to assessstudents' knowledge, promote critical thinking, and stimulate discussion. The redesigned course was offered in 2012 with 162 students meeting for a total of 25 classes. The researchers compared outcomes in the flipped classroom with those in the tradtional classroom the previous year and found attendance was higher in the flipped class and there was a statistically significant difference between final exam grades for the course in $2012(165.48 \pm 13.34)$ and in $2011(160.06 \pm 14.65)$. Furthermore, $93.1 \%$ of the 2012 students felt the teaching and learning methods in the flipped classroom promoted understanding and application of the concepts and $95.6 \%$ were confident in their ability to apply the knowledge and skills acquired.McLaughlin et al. concluded using the flipped classroom model empowers students to develop higher order thinking skills and to engage in meaningful learning.

In a study undertaken with a class of 24 pre-service teachers (Kalelioglu \& Gulbahar, 2014), six techniques were employed to draw students into thinking critically about a topic or issue. The pre-service teachers were assigned to groups for online discussions with each group utilizing one of the following techniques of communication: six thinking hats, brainstorming, role playing, socratic seminar, anyone here an expert, and mixed techniques. Though the study looked at the development of critical thinking in online discussions, it can be noted that these techniques would be applicable to classroom discussion and problem solving, as well.

The "six thinking hats" technique allowed students to engage in discussions coming from various persepectives depending on the color of hat worn at the time. These various approaches to engaging in discussion included that of inquiring about information (white hat), expressing emotions (red hat), being creative in thinking of possible solutions or new ideas (green hat), being judgmental (black hat), being optimistic (yellow hat), and thinking about their thinking process (blue hat). Role playing also allowed students to approach a problem from different perspectives depending on the role assigned. Some roles used for this sample of students were those of an administrator, student, teacher, and content specialist. The 
"anyone here an expert" technique also allowed approaches from various assigned specialities. Brainstorming is a technique that may be more familiar and one in which the students generate a plethora of relevant or irrelevant (as the case may be) ideas for problem solving without fear of criticism. The group members with assistance from the instructor then proceed to consider each, while working to narrow the focus to the better of the approaches to take. Socratic seminar utilizes interactive dialogues guiding students to generate ideas and then to justify those ideas to their own satisfaction. Finally, the mixed techniques group employed some of all the other techniques. Overall, the study found that the group using a mix of all the techniques showed gains in critical thinking both in the quantitative and qualitative results. The study also concluded, along with other cited studies (e.g. Dennen, 2002; Havard, Du \& Olinzock, 2005; Yang, 2008), that the contribution of an expert in the facilitation of discussions was important to the promotion of critical thinking habits in the discussion environment.

\section{Conclusion}

As educators try to meet the common goal of helping students to develop and/or enhance their critical thinking and problem solving skills, several factors are topics of consideration. Students who are more actively engaged are more motivated to do well. Problem solving is an effective discovery learning technique that engages students. Collaborative learning in small groups and problem solving have been shown to be effective in increasing student involvement, student interest, and student perceptions as to the value of the mathematics and of other subject content as well. Even in large classes where the scenario of the facilitation of small groups can be a daunting prospect for teachers, evidence shows that collaborative learning is an effective measure to heighten student-to-teacher interaction, as well as student-to-student interaction, and students' critical thinking skills. Because the development of critical thinking skills may be correlated to learning styles, teachers should continue to study techniques and methods to engage all students in these cognitive processes. Problem solving and critical thinking competencies are highly valued by employers in any profession. And, these competencies are widely recognized by all disciplines within the university as a central component of general education. The research points to a needed transformation of the classroom from a passive learning forum to a learning environment that focuses not only on content, but also on the goal of equipping students with lifelong cognitive skills. These skills are required for future success and are promoted in a classroom that centers student learning on problem solving, not solutions.

\section{References}

Abrami, P. C., Bernard, R. M., Borokhovski,E., Wade, A., Surkes, M. A., Tamim, R., \& Zhang, D. (2008). Instructional interventions affecting critical thinking skills and dispositions: A stage I meta-analysis. Review of Educational Research, 78(4), 1102-1134. http://dx.doi.org/10.3102/0034654308326084

Andreou, C., Papastavrou, E., \& Merkouris, A. (2013). Learning styles and critical thinking relationship in baccalaureate nursing education: A systematic review. Nurse Education Today, 34(3), 362-371. http://dx.doi.org/10.1016/j.nedt.2013.06.004 
Arum, R., Cho, E., Kim, J., \& Roksa, J. (2012). Documenting uncertain times: Postgraduate transitions of the "academically adrift" cohort. New York: Social Science Research Council. Retrieved from http://www.ssrc.org/workspace/images/crm/new_publication_3/\%7Bfcfb0e86-b346-e111-b2a 8-001cc477ec84\%7D.pdf

Baum, E.J. (2013). Augmenting guided learning with a blended classroom approach. Journal of College Science Teaching, 42(6), 27-33. http://dx.doi.org/10.2505/4/jcst13_042_06_27

Behar-Horenstein, L.S., \& Niu, L. (2011). Teaching critical thinking skills in higher education: A review of the literature. Journal of College Teaching \& Learning, 8(2), 25-41.

Bowen, C. W. (2000). A quantitative literature review of cooperative learning effects on high school and college chemistry achievement. Journal of Chemical Education, 77(1), 116-119. http://dx.doi.org/10.1021/ed077p116

Dennen, V. P. (2002). Leaning online through asynchronous discussion: Instructional design and facilitation Issues. Paper presented at American Educational Research Association Conference, New Orleans, LA.

Facione, P. A. (1990). Critical thinking: A statement of expert consensus for purposes of educational assessment and instruction. Retrieved from ERIC database. (ED315423)

Garcia, T., \& Pintrich, P. R. (1992). Critical thinking and its relationship to motivation, learning strategies, and classroom experiences. Paper presented at the annual meeting of the American Psychological Association, Washington, DC. Retrieved from ERIC database. (ED351643)

Gokhale, A. A. (1995). Collaborative learning enhances critical thinking. Journal of Technology Education, 7(1), 22-30.

Grant, N. S. (2003). A study on critical thinking, cognitive learning style, and gender in various information science programming classes. Proceedings of the $4^{\text {th }}$ Conference on Information Technology Curriculum, Lafayette, Indiana, USA, 96-99.

Haas, P. F., \& Keeley, S. M. (1998). Coping with faculty resistance to teaching criticalthinking. College Teaching, 46, 63-67.http://dx.doi.org/10.1080/87567559809596238

Halpern, D. F. (1993). Assessing the effectiveness of critical-thinking instruction. TheJournal of General Education, 42(4), 238-254.http://dx.doi.org/10.1353/jge.2001.0024

Hamouda, A.M.S., \&Tarlochan, F. (2014). Engaging engineering students in active learning and critical thinking through class debates. Procedia-Social and Behavioral Sciences,191, 990-995.

http://dx.doi.org/10.1016/j.sbspro.2015.04.379

Hancock, D. (2004). Cooperative learning and peer orientation effects on motivation and achievement. The Journal of Educational Research, 97(3), 159-168.http://dx.doi.org/10.3200/joer.97.3.159-168 


\section{Macrothink}

Journal of Studies in Education

ISSN 2162-6952

2015, Vol. 5, No. 4

Havard, B., Du, J., \&Olinzock, A. (2005). Deep learning: The knowledge, methods, and cognition process in instructor-led online discussion. The Quarterly Review of Distance Education, 6(2), 125-135.

Johnson, D. W., Johnson, R. T., \& Smith, K. A. (1998). Cooperative learning returns to college: What evidence is there that it works?Change, 30(4), 26-35.http://dx.doi.org/10.1080/00091389809602629

Kalelioglu, F., \&Gulbahar, Y. (2014). The Effect of Instructional Techniques on Critical Thinking and Critical Thinking Dispositions in Online Discussion. Educational Technology \& Society, 17 (1), 248-258.

Kim, K., Sharma, P., Land, S. M., \& Furlong, K. P. (2012). Effects of active learning on enhancing student critical thinking in an undergraduate general science course. Innovative Higher Education, 38(3), 223-235.http://dx.doi.org/ 10.1007/s10755-012-9236-x

Kozulin, A. (2004). Vygotsky's theory in the classroom: Introduction. European Journal of Psychology of Education, 21(1),3-7.http://dx.doi.org/10.1007/bf03173233

Lai, E.R. (2011). Critical thinking: A literature review. Pearson's Research Reports, 6, 40-41. Retrieved from http://images.pearsonassessments.com/images/tmrs/CriticalThinkingReviewFINAL.pdf

Lockwood, J. S. (2007). Motivating liberal arts math students through problem solving.

Retrieved

from http://college.hmco.com/reviewers_authors/mathpremiere/excursions/excursions_newsletter. pdf.

Maddux, C. D., Johnson, D. L., Willis, J. W. (1997). Educational Computing: Learning with

Tomorrow’s Technologies. Retrieved from http://viking.coe.uh.edu/ ichen/ebook/etit/4vygo.htm

Magel, R. C. (1996). Increasing student participation in large introductory statistics classes. The American Statistician, 50(1), 51-66.http://dx.doi.org/10.1080/00031305.1996.10473542

Mahalingam, M., Schaefer, F., \&Morlino, E. (2008). Promoting student learning through group problem solving in general chemistry recitations. Journal of Chemical Education, 85(11), 1577-1581.http://dx.doi.org/10.1021/ed085p1577

McLaughlin, J.E., Roth, M.T., Glatt, D.M., Gharkholonarehe, N., Davidson, C.A., Griffin, L.M., Esserman, D.A., \&Mumper, R.J. (2014). The flipped classroom: A course redesign to foster learning and engagement in a health professions school. Academic Medicine, 89(2), 236-243. http://dx.doi.org/10.1097/ACM.0000000000000086 
Myers, B. E., \& Dyer, J. E. (2006). The influence of student learning style on critical thinking skill. Journal of Agricultural Education, 47(1), 43-52. http://dx.doi.org/10.5032/jae.2006.01043

National Council of Teachers of Mathematics. (1989). Curriculum and evaluation standards for school mathematics. Reston, VA: The National Council of Teachers of Mathematics, Inc.

Norman, D. A., \&Spohrer, J. C. (1996). Learner-centered education. Communications of the ACM,39(4), 24-27.http://dx.doi.org/10.1145/227210.227215

Paul, R. W. (1992). Critical thinking: What, why, and how? New Directions for Community Colleges, 1992(77), 3-24.http://dx.doi.org/10.1002/cc.36819927703

Prince, M. (2004). Does active learning work? A review of the research. Journal of Engineering Education, 93(3), 223-231. http://dx.doi.org/10.1002/j.2168-9830.2004.tb00809.x

Reiff, J. C. (1996). At-risk middle level students or field dependent learners? TheClearing House, 69(4), 231-234.

"Relevance of Collaborative Leaning in Classrooms." Education, 21 September 2014. Transcript. Retrieved from http://www.slideshare.net/tsparvathi/relevance-ofcollaborative-learning-in-classrooms-39339 224

Rugutt, J., \&Chemosit, C. C., (2009). What motivates students to learn? Contribution of student-to-student relations, student-faculty interaction and critical thinking skills. Educational Research Quarterly, 32(3), 16-28.

Snyder, L. G., \& Snyder, M. J. (2008). Teaching critical thinking and problem solving skills. TheDelta Pi Epsilon Journal. 50(2), 90-99.

"The Effects of Computer-Assisted Instruction on Problem Solving and Critical Thinking."(n.d.). Retrieved from http://citeseerx.ist.psu.edu/viewdoc/download?doi=10.1.1.130.6838\&rep=rep1\&type=pdf

Torres, R. M., \& Cano, J. (1995). Critical thinking as influenced by learning style. Journal of Agricultural Education, 36, 55-63.http://dx.doi.org/10.5032/jae.1995.04055

Weissglass, J. (1993). Small-group learning. The American Mathematical Monthly, 100(7), 662-668.http://dx.doi.org/10.2307/2323888

Willingham, D. T. (2008). Critical thinking: Why is it so hard to teach? Arts Education Policy Review, 109(4), 21-29.http://dx.doi.org/10.3200/aepr.109.4.21-32

Wulff, S. S., \&Wulff, D. H. (2004). “Of course I'm communicating; I lecture everyday": Enhancing teaching and learning in introductory statistics. Communication Education,53(1), 92-103.http://dx.doi.org/10.1080/0363452032000135797 


\section{Macrothink}

Journal of Studies in Education ISSN 2162-6952

Yang, Y. C. (2007). A catalyst for teaching critical thinking in a large university class in Taiwan: Asynchronous online discussions with the facilitation of teaching assistants. Education Technology Research and Development, 56(3), 241-264.http://dx.doi.org/10.1007/s11423-007-9054-5 